Understanding the kinetics of thermal decomposition of 2,3-epoxy-2,3-dimethylbutane using RRKM theory

Peer-reviewed author version

SHIROUDI, Abolfazl \& Zahedi, Ehsan (2016) Understanding the kinetics of thermal decomposition of 2,3-epoxy-2,3-dimethylbutane using RRKM theory. In: RSC advances, 6(94), p. 91882-91892.

DOI: $10.1039 / C 6 R A 21963 B$

Handle: http://hdl.handle.net/1942/22518 


\title{
Understanding the kinetics of thermal decomposition of
} 2,3-epoxy-2,3-dimethylbutane using RRKM theory

\author{
Abolfazl Shiroudi ${ }^{a, b, *}$, Ehsan Zahedi ${ }^{c}$ \\ ${ }^{a}$ Center of Molecular and Materials Modelling, Hasselt University, Agoralaan, Gebouw D, B-3590 Diepenbeek, Belgium \\ ${ }^{b}$ Young Researchers and Elite Club, East Tehran Branch, Islamic Azad University, Tehran, Iran \\ ${ }^{c}$ Chemistry Department, Shahrood Branch, Islamic Azad University, Shahrood, Iran
}

\begin{abstract}
The thermal decomposition kinetics of 2,3-epoxy-2,3-dimethylbutane have been studied computationally using density functional theory, along with various exchange-correlation functionals and an extremely large basis set. The calculated energy profiles have been supplemented with calculations of kinetic rate constants and branching ratios under atmospheric pressure and in the fall-off regime have been supplied, using transition state theory (TST) and statistical Rice-Ramsperger-Kassel-Marcus (RRKM) theory. Kinetic rate constants and branching ratios under atmospheric pressure and in the fall-off regime have been supplied, using transition state and RRKM theories. By comparison with experiment, all our calculations indicate that, from a kinetic viewpoint, the most favorable process is thermal decomposition of 2,3-epoxy-2,3-dimethylbutane into the 2,3-dimethylbut-3-en-2-ol, whereas under thermodynamic control of the reactions, the most abundant product derived from the 2,3-epoxy-2,3-dimethylbutane species will be the 3,3-dimethylbutan-2-one species. The regioselectivity of the decomposition decreases with increasing temperatures and decreasing pressures. In line with rather larger energy barriers, pressures larger than $10^{-6}$ bar are in general sufficient for ensuring a saturation of the computed unimolecular kinetic rate constants compared with the high-pressure limit (TST) of the RRKM unimolecular rate constants. The bonding evolution theory indicated that thermal decomposition of 2,3-epoxy2,3-dimethylbutane into the 2,3-dimethylbut-3-en-2-ol takes place along three differentiated successive structural stability domains after passing the reactant from the associated transition state.
\end{abstract}

Keywords: 2,3-epoxy-2,3-dimethylbutane, decomposition, energy barriers, rate constants, unimolecular reaction, reaction mechanisms.

\footnotetext{
${ }^{*}$ Corresponding author: E-mail: abolfazl.shiroudi@uhasselt.be (A. Shiroudi)
} 


\section{Introduction}

Pyrolysis of ethylene oxide ${ }^{1,2}$ and propylene oxide ${ }^{2,3}$ is complicated by the occurrence of primary and secondary radical reactions in addition to the non-radical processes. It was hoped that a tetra-substituted ethylene oxide would be less susceptible to radical attack and would therefore provide clearer evidence as to the mechanism of epoxide decomposition. The decompositions of ethylene oxide and propylene oxide have been explained in terms of a mechanism involving the initial fission of the ring to form a biradical intermediate of short lifetime that can either recyclize or rearrange to give the observed products. ${ }^{4}$ Flowers et al. ${ }^{5}$ have suggested similar argument for the thermal decomposition of 2,3-epoxy-2,3dimethylbuthane (see Scheme 1):

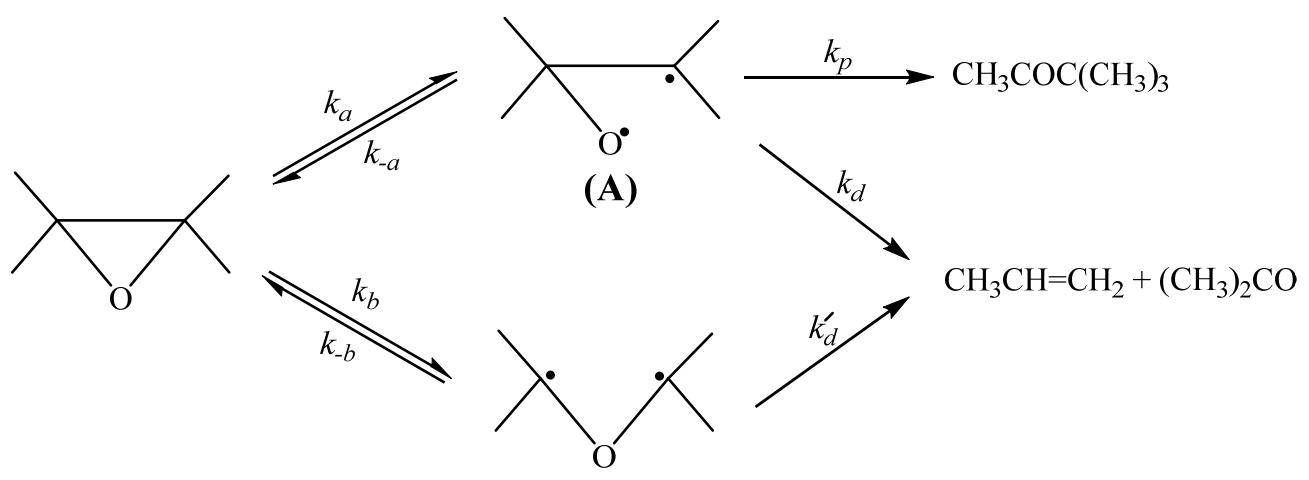

(B)

Scheme 1

Formation of 3,3-dimethylbutan-2-one however is most conveniently explained as arising via a methyl shift in intermediate A. Fragmentation of either $\mathbf{A}$ or $\mathbf{B}$ would lead to the formation of propene and acetone via a transition state involving simultaneous migration of a hydrogen atom in the dimethylmethylene fragment. They have noted that, it is not possible to decide whether one or both of the intermediates participate in this reaction as although formation of $\mathbf{B}$ from the epoxide is probably favored over $\mathbf{A}$, this may be more than compensated for in the rates of decomposition of the two intermediates. ${ }^{5}$ Also, they discussed that the mechanism for the formation of 2,3-dimethylbut-3-en-2-ol is more difficult to explain. A 1,4-hydrogen shift to the oxygen in intermediate A would appear the logical route but for the fact that the measured activation energy is lower than the estimated bond dissociation energy to give A. They have suggested that an analogous reaction to explain the formation of acetone and propene, i.e., a 1,4-hydrogen transfer in biradical $\mathbf{B}$ to give 
isopropenylisopropyl ether which then, via a 1,5-hydrogen transfer, decomposes rapidly to acetone and propene. This mechanism conveniently explains the formation of methyl vinyl ether, which cannot decompose via a 1,5-hydrogen shift, in the pyrolysis of propylene oxide. ${ }^{3 \mathrm{c}}$ Intermediate B structurally offers no route to the alcohol. Also, they have noted that an alternative is that formation of the alcohol occurs via a concerted reaction from the epoxide. However the highly strained nature of the bicyclic transition state that would be involved makes this unsatisfactory also. A further possibility is that, in spite of the negative findings regarding the importance of surface or radical reactions in the formation of the alcohol, the Arrhenius parameters measured are not those of an elementary reaction. Finally, they have concluded that the radical process in ethylene and propylene oxides decompositions, that may arise as the result of decomposition of the product aldehyde owing to its formation with a large energy excess are not important in their study. ${ }^{1 \mathrm{c}, 4}$ This is to be expected as 3,3dimethylbutan-2-one has a greater number of internal degrees of freedom and the reaction has a smaller exothermicity.

The kinetics of the gas-phase thermal decomposition of 2,3-epoxy-2,3-dimethylbutane has been measured or experimentally inferred in the temperature range from 661.5 to $729.1 \mathrm{~K}$, and at a pressure of 11 Torr indicated that the decomposition processes carried out by three competing homogeneous, first-order, and non-radical reactions to give either 3,3dimethylbutan-2-one (reaction 1), or propene and acetone (reaction 2), and 2,3-dimethylbut-3en-2-ol (reaction 3).

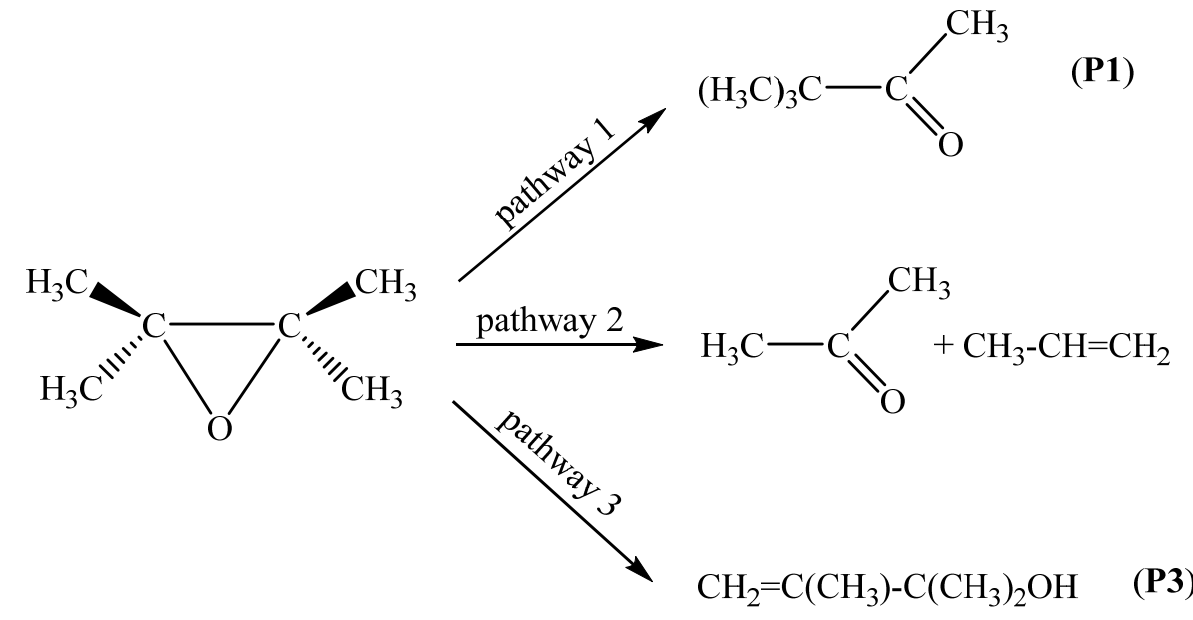

Figure 1. Thermal decomposition of 2,3-epoxy-2,3-dimethylbutane via chemical reaction pathways 1-3

An Arrhenius plot of all the experimental unimolecular rate constants of 2,3-epoxy-2,3dimethylbutane is depicted in Figure $2 .^{5}$ As is immediately apparent from this figure, for 
all reported series of data, the rate constant of the gas-phase unimolecular decomposition of 2,3-epoxy-2,3-dimethylbutane exhibit positive temperature dependences over the studied temperature range, which is equivalent to Arrhenius activation energies of $(-56.7 \pm 1.36)$, $(-59.22 \pm 2.4)$, and $(-47.5 \pm 2.05) \mathrm{kcal} \mathrm{mol}^{-1} \cdot 5$ A least-square fit of the experimental rate constants yields accordingly the following Arrhenius expressions: ${ }^{5}$

$$
\begin{aligned}
& k_{1}=10^{(13.83 \pm 0.43)} \exp [-(56700 \pm 1360) / R T] ;(\text { Reaction 1) } \\
& k_{2}=10^{(14.77 \pm 0.76)} \exp [-(59220 \pm 2400) / R T] ;(\text { Reaction 2) } \\
& k_{3}=10^{(10.88 \pm 0.65)} \exp [-(47500 \pm 2050) / R T] ;(\text { Reaction 3) }
\end{aligned}
$$

A first-order plot for epoxide decomposition shows slight curvature, but indicates that the overall reaction is approximately of the first order at a pressure of 11 Torr. Reaction mechanisms are discussed in which the initial step is fission of the ring at either a $\mathrm{C}-\mathrm{C}$ or a $\mathrm{C}-\mathrm{O}$ bond to give a short-lived biradical intermediate that may rearrange or decompose to give the observed products. The ratio of 3,3-dimethylbutan-2-one to propene was constant at each temperature, therefore the production of each is of the first order.

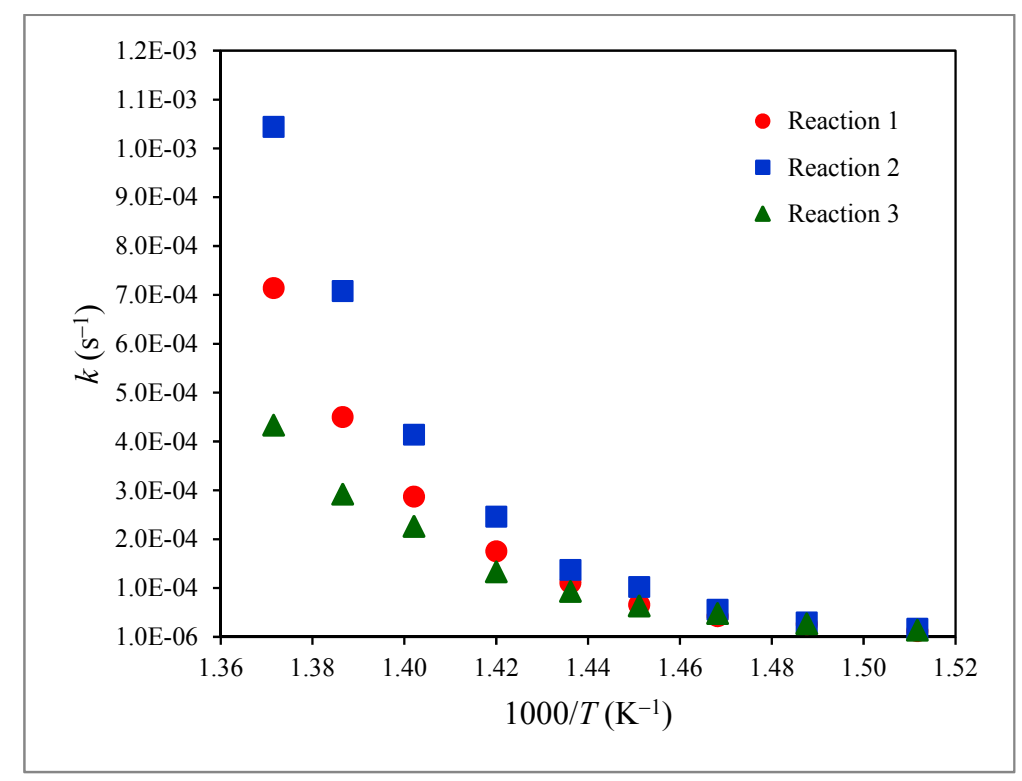

Figure 2. Arrhenius plot of the experimental rate constant of the unimolecular thermal decomposition processes of 2,3-epoxy-2,3-dimethylbutane. ${ }^{5}$ Legend: $(\boldsymbol{\bullet})$ Reaction 1; (ם) Reaction 2; ( $\left.\boldsymbol{\Delta}\right)$ Reaction 3.

The basic interest of the present study is to understand the activation energies as well as kinetic rate constants of the molecular mechanism of the thermal decomposition processes of 2,3-epoxy-2,3-dimethylbutane that are displayed in Figure 1. In this purpose, we use shall be 
made of transition state theory (TST), ${ }^{6-13}$ in conjunction with the dispersion-corrected $\omega \mathrm{B} 97 \mathrm{XD}^{14}$ and the UM06- $2 x^{15}$ exchange-correlation functionals and Dunning's augmented correlation consistent polarized valence basis set of triple zeta quality (aug-cc-pVTZ). ${ }^{16}$

In addition, kinetic rate constants at the high pressure limit will be supplied by means of TST, and their fall-off behavior at lower pressures will be studied using statistical Rice-Ramsperger-Kassel-Marcus (RRKM) theory, ${ }^{17-19}$ for the purpose of unraveling the detailed experiments by Flowers et al. ${ }^{5}$ at temperature ranging from 661.5 to $729.1 \mathrm{~K}$.

\section{Computational details}

All calculations that are discussed in the present work have been performed using the Gaussian 09 package of programs. ${ }^{20}$ Molecular structures were visualized using GaussView. ${ }^{21}$ The molecular structures and harmonic vibrational frequencies of all stationary points of interest were calculated using density functional theory (DFT) along with the $\omega \mathrm{B} 97 \mathrm{XD}$ and UM06-2x exchange-correlation functionals, in conjunction with diffuse functions (aug-ccpVTZ basis set). The nature of all identified stationary points has been verified according to calculations of harmonic vibrational frequencies at the same level of theory as the geometry optimization. The intrinsic reaction coordinates (IRC) calculation was performed in forward and backward along the reaction path to identify whether the located transition state structure connects to the two associated minima, using the Hessian based predictor corrector (HPC) integrator algorithm. ${ }^{22}$

In line with the temperatures at which the experiments by Flowers et al. ${ }^{5}$ were conducted, unimolecular rate constants and branching ratios have been obtained at temperature ranging from 661.5 to $729.1 \mathrm{~K}$ and at a pressure of 1 bar (high pressure limit) using transition state theory (TST), and the UM06-2x/aug-cc-pVTZ has been used to estimates the activation energies ( $E_{a}$ [including zero-point vibrational energy (ZPVE) contributions]). The rationale behind choosing the UM06-2 $x$ exchange-correlation functional is that a recent study by Zhao and $\operatorname{Truhlar}^{15}$ has shown that it is the best one for applications involving main-group thermochemistry, kinetics, noncovalent interactions, and electronic excitation energies to valence and Rydberg states. M06-2x exchange-correlation functional and its analogs are dedicated for precisely energetic considerations. However, recently it has been established that this approach underestimate activation parameters for many addition reactions, ${ }^{23}$ whereas for elimination processes the same methodology overestimate activation parameters. ${ }^{24}$ 
In atmospheric chemistry, the kinetics of unimolecular reactions can be determined using conventional TST. The rate constants for unimolecular reactions are therefore given by: $:^{25-27}$

$$
k_{\mathrm{uni}}=\kappa(T) \frac{\sigma k_{\mathrm{B}} T}{h} \frac{Q_{\mathrm{TS}}^{\neq}(T)}{Q_{\mathrm{R}}(T)} \exp \left(-E_{a} / R T\right)
$$

along with $k_{\mathrm{B}}, h$ and $R$ are the Boltzmann's, Planck's and ideal gas constants, respectively. In the above equation, $\sigma$ is the reaction symmetry number, and $\kappa(T)$ denotes the Wigner's tunneling factor ${ }^{28}$ that has been considered for evaluating the rate constant of the unimolecular dissociation step on TST grounds, using the UM06- $2 x$ energy profiles. The Wigner tunneling factor is given by:

$$
\kappa(T)=1+\frac{1}{24}\left(\frac{h \operatorname{Im}\left(v_{i}\right)}{k_{B} T}\right)^{2}
$$

where $\operatorname{Im}\left(v_{i}\right)$ is the imaginary vibrational frequency of the relevant transition state.

Since the computed energy differences account for ZPVEs, vibrational partition functions were computed using the vibrational ground state as energy reference. TST gives an estimate of the upper-limit for rate constants as a function of the temperature, and is known to give reliable estimations of rate constants ${ }^{19,29}$ in the high pressure limit, especially for cases with significant barrier heights.

Note that, in practice, standard atmospheric pressures ( 1 bar) are usually considered to be large enough for reliably calculating kinetic rate constants by means of TST. The fall-off behavior of canonical kinetic rate constants from the TST limit $(P \rightarrow \infty)$ towards the lowpressure limit $(P \rightarrow 0)$ has been also studied using statistical RRKM theory. ${ }^{17-19}$ The RRKM microcanonical rate constants $k(E)$ are given by the standard expression: ${ }^{17}$

$k(E)=\frac{\sigma N^{\dagger}(E)}{h \rho(E)}$

where $\rho(E)$ represents the density of states at the reactants, and $N^{\dagger}(E)$ denotes the total number of states at the transition state with energy less than or equal to $E$.

In the present work, all supplied TST, and RRKM rate constants are the results of chemical kinetic calculations that were performed by means of the Kinetic and Statistical Thermodynamical Package (KiSThelP). ${ }^{30}$ All these calculations rely upon UM06-2x/aug-ccpVTZ estimations of activation energies and ro-vibrational densities of states. A scaling factor of 0.971 was imposed on the frequencies calculated at the UM06-2x/aug-cc-pVTZ level in the RRKM calculations. Lennard-Jones (LJ) collision rate theory was used to evaluate collisional stabilization rate constants. ${ }^{31}$ The strong collision approximation is used assuming that every 
collision deactivates with $\omega=\beta_{\mathrm{c}} \cdot Z_{\mathrm{LJ}} .[\mathrm{M}]$ being the effective collision frequency, where $\beta_{\mathrm{c}}$ is the collisional efficiency, $\mathrm{Z}_{\mathrm{LJ}}$ represents the LJ collision frequency, and $[\mathrm{M}]$ is the total gas concentration. The collision frequencies $\left(Z_{\mathrm{LJ}}\right)$ were calculated using the LJ parameters: $\varepsilon / k_{\mathrm{B}}$, which depends on the energy depth $(\varepsilon)$ of the LJ potential and $\sigma$, which represents a dimensional scale of the molecular radius. The retained LJ potential parameters were $\sigma=3.465$ $\AA$ and $\varepsilon / k_{\mathrm{B}}=113.5 \mathrm{~K}$ for argon as diluent gas, ${ }^{29}$ and $\sigma=5.7 \AA$ and $\varepsilon / k_{\mathrm{B}}=447.1 \mathrm{~K}$ for the 2,3epoxy-2,3-dimethylbutane. ${ }^{32}$

\section{Results and discussions}

\section{Energetic and thermodynamic parameters}

Reaction energies, enthalpies, entropies and Gibb's free reaction energies for the thermal decomposition of 2,3-epoxy-2,3-dimethylbutane is supplied in Table 1. In line with experimental Arrhenius activation energies, ${ }^{5}$ all DFT calculations most clearly show that decomposition of reactant via pathway 2 in the gas-phase is endothermic process $(\Delta H \approx$ 2.82-5.11 kcal mol ${ }^{-1}$ ) whereas for the reaction pathways $\mathbf{1}$ and $\mathbf{3}$ are exothermic processes at the DFT levels of theory $\left[\Delta H \approx(-19.58)-(-17.48)\right.$, and $(-4.62)-(-3.66) \mathrm{kcal} \mathrm{mol}^{-1}$, respectively]. All unimolecular pathways $\mathbf{1}-\mathbf{3}$ are exoergic processes $(\Delta G<0)$ at ambient temperature and pressure. From the energy profiles supplied in Figure 3 and Table 1, it is clear that among all produced products, the formation of 3,3-dimethylbutan-2-one (via reaction 1) is the most stable structure and the $\mathbf{P 1}$ species will be thermodynamically favored, since the reaction pathway 1 is exothermic $\left[\Delta H \approx(-19.58)-(-17.48) \mathrm{kcal} \mathrm{mol}^{-1}\right]$ and strongly exoergic $\left[\Delta G \approx-(-20.03)-(-16.82) \mathrm{kcal} \mathrm{mol}^{-1}\right]$.

Table 1. Reaction energies, reaction enthalpies and Gibb's free reaction energies (in kcal $\mathrm{mol}^{-1}$ ) for the decomposition of 2,3-epoxy-2,3-dimethylbutane via pathways 1-3 at different DFT levels of theory. $(P=1 \mathrm{~atm})$

\begin{tabular}{lccccccccc}
\hline & \multicolumn{3}{c}{ Method } & \multicolumn{3}{c}{$\omega \mathrm{B} 97 \mathrm{XD} /$ aug-cc-pVTZ } & & \multicolumn{3}{c}{ UM06-2x/aug-cc-pVTZ } \\
\cline { 8 - 9 } Species & $\Delta E_{0 \mathrm{~K}}$ & $\Delta H^{\circ}{ }_{298 \mathrm{~K}}$ & $\Delta G^{\circ}{ }_{298 \mathrm{~K}}$ & & $\Delta E_{0 \mathrm{~K}}$ & $\Delta H^{\circ}{ }_{298 \mathrm{~K}}$ & $\Delta G^{\circ}{ }_{298 \mathrm{~K}}$ \\
\hline 2,3-epoxy-2,3-dimethylbutane (R) & 0.00 & 0.00 & 0.00 & & 0.00 & 0.00 & 0.00 \\
3,3-dimethylbutan-2-one (P1) & -19.58 & -19.43 & -20.03 & & -17.48 & -17.60 & -16.82 \\
Propene + acetone (P2) & 1.93 & 2.82 & -10.19 & & 4.32 & 5.11 & -7.28 \\
2,3-dimethylbut-3-en-2-ol (P3) & -3.66 & -3.82 & -3.24 & & -4.62 & -4.89 & -3.62 \\
\hline
\end{tabular}


Table 2. Activation energies, enthalpies and Gibb's free activation energies (in $\mathrm{kcal} \mathrm{mol}^{-1}$ ), and activation entropies (in cal $\mathrm{mol}^{-1} \mathrm{~K}^{-1}$ ) of transition states relative to the reactant along chemical pathways 1-3 at different DFT levels of theory. $(P=1 \mathrm{~atm})$

\begin{tabular}{|c|c|c|c|c|c|c|c|}
\hline \multirow[b]{2}{*}{ Species } & \multicolumn{3}{|c|}{$\omega \mathrm{B} 97 X \mathrm{XD} / \mathrm{aug}-\mathrm{cc}-\mathrm{pVTZ}$} & \multicolumn{3}{|c|}{ UM06-2x/aug-cc-pVTZ } & \multirow{2}{*}{$\begin{array}{c}\text { literature [5] } \\
\Delta E_{0 \mathrm{~K}}^{\dagger}\left(\mathrm{kcal} \mathrm{mol}^{-1}\right)\end{array}$} \\
\hline & $\Delta E_{0 \mathrm{~K}}^{\dagger}$ & $\Delta H^{\circ}{ }_{298 \mathrm{~K}}^{\dagger}$ & $\Delta G^{\circ}{ }_{298 \mathrm{~K}}^{\dagger}$ & $\Delta E_{0 \mathrm{~K}}^{\dagger}$ & $\Delta H^{\circ}{ }_{298 \mathrm{~K}}^{\dagger}$ & $\Delta G_{298 \mathrm{~K}^{\dagger}}^{\circ}$ & \\
\hline $\mathrm{R}$ & 0.00 & 0.00 & 0.00 & 0.00 & 0.00 & 0.00 & \\
\hline TS1 & 56.82 & 56.71 & 57.13 & 60.48 & 60.22 & 61.50 & 56.70 \\
\hline Imaginary frequency TS1 $\left(\mathrm{cm}^{-1}\right)$ & $338.73 i$ & & & $360.94 i$ & & & \\
\hline TS2 & 53.45 & 53.28 & 53.56 & 66.34 & 65.92 & 67.52 & 59.22 \\
\hline Imaginary frequency TS2 $\left(\mathrm{cm}^{-1}\right)$ & $192.39 i$ & & & $234.59 i$ & & & \\
\hline TS3 & 57.26 & 56.90 & 57.995 & 59.37 & 59.04 & 60.40 & 47.50 \\
\hline Imaginary frequency TS3 $\left(\mathrm{cm}^{-1}\right)$ & $2005.28 i$ & & & $1990.36 i$ & & & \\
\hline
\end{tabular}

Note that, whatever the employed exchange-correlation functional (UM06-2x), the energy barrier $\left(\Delta E_{0 \mathrm{~K}}^{\dagger}\right)$ for the reaction pathway 3 is lower than the barrier for chemical reactions $\mathbf{1}$ and 2. Similar observations can be made when Gibb's free activation energies are considered: in spite of slightly unfavorable entropy effects, the Gibb's free energy for reaction pathway 3 $\left(60.4 \mathrm{kcal} \mathrm{mol}^{-1}\right)$ is lower than the ones for the pathways 1 and $2\left(61.5\right.$ and $67.5 \mathrm{kcal} \mathrm{mol}^{-1}$, respectively). This difference in activation energies, and Gibb's free activation energies for these unimolecular reaction pathways 1-3 indicates (see Figure 3) that the formation of 2,3dimethylbut-3-en-2-ol species (P3) will be kinetically favored over the formation of the other products (P1 and P2). The activation energies from the UM06-2x/aug-cc-pVTZ level of theory in comparison to the other theoretical method ( $\omega$ B97XD) are in good agreement with the experimental values ${ }^{5}$ and show that the barrier height of the decomposition of reaction pathways 1-3 are 60.48, 66.34, and $59.37 \mathrm{kcal} \mathrm{mol}^{-1}$, respectively. Energy profile for decomposition processes $\mathbf{1}-\mathbf{3}$ is depicted in Figure 3.

Whatever this chemical reaction via pathway 3 is kinetically favored over the other pathways, while the formation of the 3,3-dimethylbutan-2-one species (P1) will clearly predominate under thermodynamic control, i.e. at chemical equilibrium. 


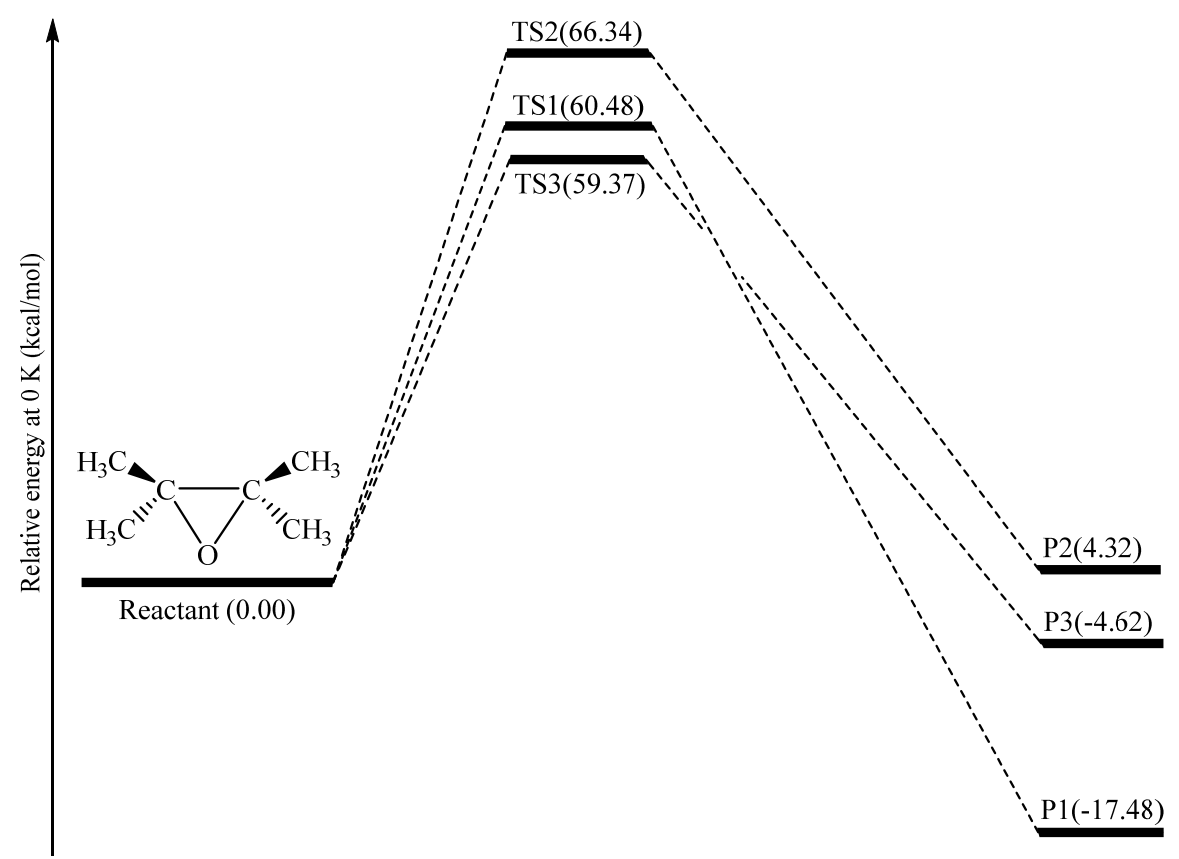

Figure 3. Potential energy diagram for the reaction pathways 1-3 at the UM06-2x/aug-cc-pVTZ level of theory.

\section{Structural characteristics of stationary points}

The optimized geometries of all identified stationary points [reactant (R), transition states (TS1, TS2, and TS3), and products (P1, P2, and P3)] involved in the chemical pathways 1-3 are supplied at all selected DFT levels in Table 3. The reader is correspondin4gly referred to Figure 4 for detailed atom labelling.

Table 3. Structural parameters for all stationary points which are involved in the chemical reaction pathways $\mathbf{1}-\mathbf{3}$. $(T=298 \mathrm{~K})$

\begin{tabular}{|c|c|c|c|c|c|c|c|c|c|c|c|c|c|c|}
\hline \multirow{2}{*}{ Parameter } & \multicolumn{7}{|c|}{$\omega \mathrm{B} 97 \mathrm{XD} /$ aug-cc-pVTZ } & \multicolumn{7}{|c|}{ UM06-2x/aug-cc-pVTZ } \\
\hline & $\mathrm{R}$ & TS1 & TS2 & TS3 & $\mathrm{P} 1$ & $\mathrm{P} 2$ & P3 & $\mathrm{R}$ & TS1 & TS2 & TS3 & P1 & $\mathrm{P} 2$ & $\mathrm{P} 3$ \\
\hline$r\left(\mathrm{O}_{1}-\mathrm{C}_{2}\right)$ & 1.430 & 1.324 & 2.440 & 1.967 & 1.206 & - & - & 1.428 & 1.328 & 3.112 & 1.910 & 1.206 & - & - \\
\hline$r\left(\mathrm{O}_{1}-\mathrm{C}_{3}\right)$ & 1.430 & 2.282 & 1.291 & 1.441 & - & 1.205 & 1.422 & 1.428 & 2.270 & 1.250 & 1.422 & - & 1.205 & 1.422 \\
\hline$r\left(\mathrm{C}_{2}-\mathrm{C}_{3}\right)$ & 1.476 & 1.478 & 2.911 & 1.500 & 1.535 & - & 1.527 & 1.479 & 1.476 & 3.134 & 1.491 & 1.530 & - & 1.523 \\
\hline$r\left(\mathrm{C}_{2}-\mathrm{C}_{4}\right)$ & 1.511 & 1.591 & 1.375 & 1.410 & 1.513 & 1.324 & 1.327 & 1.509 & 1.587 & 1.387 & 1.413 & 1.513 & 1.324 & 1.328 \\
\hline$r\left(\mathrm{C}_{2}-\mathrm{C}_{5}\right)$ & 1.511 & 1.548 & 1.498 & 1.486 & - & 1.495 & 1.503 & 1.510 & 1.545 & 1.499 & 1.489 & - & 1.495 & 1.503 \\
\hline$r\left(\mathrm{C}_{3}-\mathrm{C}_{6}\right)$ & 1.511 & 1.473 & 1.551 & 1.522 & 1.533 & 1.510 & 1.531 & 1.510 & 1.473 & 1.506 & 1.517 & 1.531 & 1.510 & 1.529 \\
\hline$r\left(\mathrm{C}_{3}-\mathrm{C}_{7}\right)$ & 1.511 & 1.462 & 1.539 & 1.524 & 1.538 & 1.510 & 1.527 & 1.509 & 1.463 & 1.505 & 1.520 & 1.536 & 1.510 & 1.525 \\
\hline$r\left(\mathrm{C}_{3}-\mathrm{C}_{5}\right)$ & - & 2.383 & - & - & 1.526 & - & - & - & 2.385 & - & - & 1.524 & - & - \\
\hline$r\left(\mathrm{C}_{4}-\mathrm{H}_{8}\right)$ & 1.085 & - & 1.517 & 1.330 & - & - & - & 1.085 & - & 1.462 & 1.349 & - & - & - \\
\hline$r\left(\mathrm{O}_{1}-\mathrm{H}_{8}\right)$ & 2.658 & - & - & 1.421 & - & - & 0.959 & 2.683 & - & - & 1.397 & - & - & 0.962 \\
\hline$r\left(\mathrm{C}_{2}-\mathrm{H}_{8}\right)$ & 2.171 & - & 1.180 & - & - & 1.086 & - & 2.170 & - & 1.324 & - & - & 1.086 & - \\
\hline$\angle \mathrm{H}_{8}-\mathrm{C}_{4}-\mathrm{C}_{2}$ & 112.5 & - & - & 73.5 & - & - & - & 112.6 & - & - & 71.9 & - & - & - \\
\hline$\angle \mathrm{H}_{8}-\mathrm{O}_{1}-\mathrm{C}_{3}$ & 79.5 & - & - & 91.2 & - & - & 108.3 & 77.8 & - & - & 92.1 & - & - & 108.3 \\
\hline
\end{tabular}

\footnotetext{
Bond lengths are given in angstroms $(\AA)$, and angles are given in degrees $\left({ }^{\circ}\right)$
} 

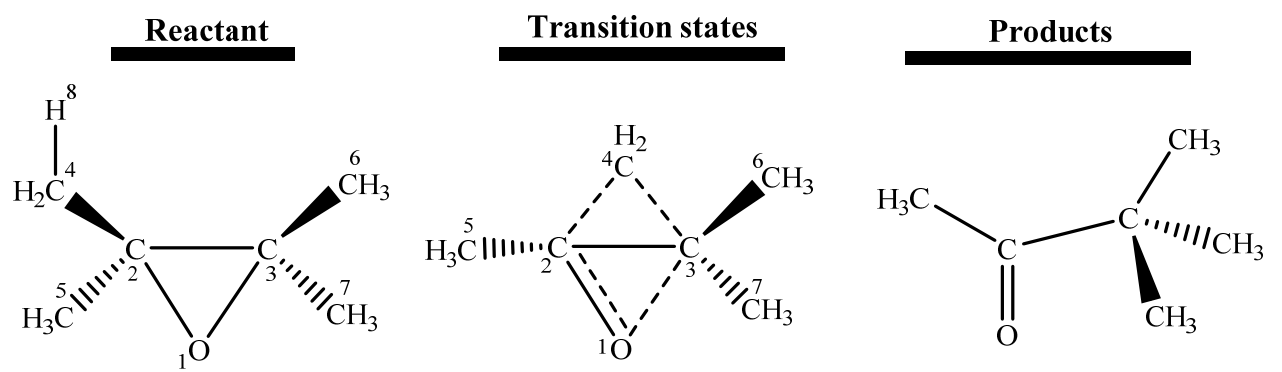

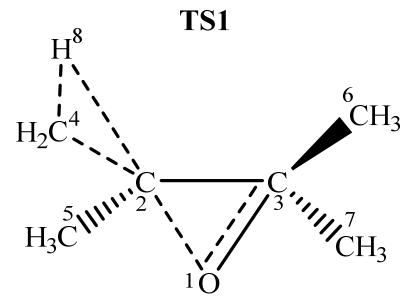

TS2

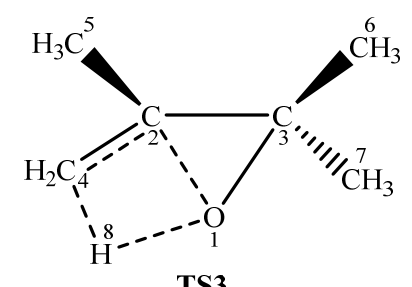

TS3

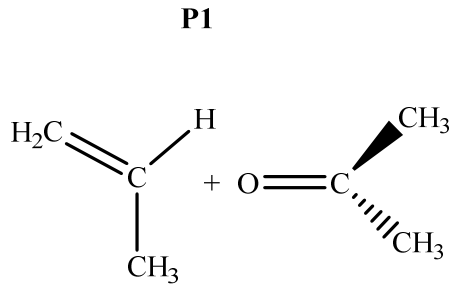

P2

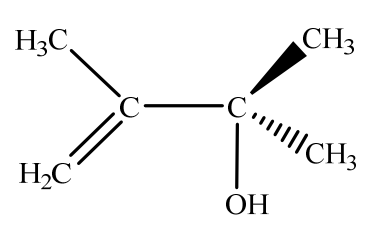

P3

Figure 4. Geometries of the reactant, transition states, and products that are involved in the thermal decomposition processes.

Hammond's postulate states that the structure of a transition state resembles that of the species nearest to it in free energy. ${ }^{33}$ This principle is usually quantified in terms of the position of the transition structure along the reaction coordinate, $n_{\mathrm{T}}$, as defined by Agmon ${ }^{34}$

$n_{\mathrm{T}}=\frac{1}{2-\left(\Delta G / \Delta G^{\dagger}\right)}$

The magnitude of $n_{\mathrm{T}}$ indicates the degree of similarity between the transition structure and the product. According to this equation, the position of the transition state along the reaction coordinate is determined solely by the Gibbs free energy of reaction, $\Delta G$ (a thermodynamic quantity), and the Gibbs free activation energy, $\Delta G^{\dagger}$ (a kinetic quantity).

Table 4. Analysis of the chemical pathways of interest in terms of $n_{\mathrm{T}}$ values.

\begin{tabular}{|c|c|c|}
\hline Pathway Method & $\omega \mathrm{B} 97 \mathrm{XD}$ & UM06- $2 x$ \\
\hline $\mathrm{R} \rightarrow$ 3.3-dimethylbutan-2-one & 0.4254 & 0.4398 \\
\hline $\mathrm{R} \rightarrow$ Propene + acetone & 0.4688 & 0.4744 \\
\hline $\mathrm{R} \rightarrow$ 2.3-dimethylbut-3-en-2-ol & 0.4864 & 0.4855 \\
\hline
\end{tabular}


In line with the previously obtained energy profiles (Figure 3), and the structural observations made in the preceding section, the obtained values imply that at all considered levels of theory, the transition states involved in the formation of the products P1-P3 are more similar to the reactant (Table 4).

\section{Kinetic parameters}

TST and RRKM unimolecular rate constants of the thermal decomposition processes of 2,3-epoxy-2,3-dimethylbutane in the gas-phase calculated along with the UM06-2x/aug-ccpVTZ approach are listed in Table 5 at a pressure of 1 bar and at the considered temperatures, in line with the original experiments by Flowers et al. ${ }^{5}$ Further RRKM data computed at lower and higher pressures are provided for the same temperatures in Tables S1a-S1 $i$ of the Supplementary information.

The supplied unimolecular TST and RRKM results obtained along with the UM06-2x approach indicate that, at a pressure of 1.0 bar, the formation of the product P3 [2,3dimethylbut-3-en-2-ol species] will clearly predominate over the formation of the 3,3dimethylbutan-2-one (via reaction 1), or propene and acetone (via reaction 2) (see Figure 5). Note that, in line with a lower activation energy, the kinetically most competitive process corresponds to the unimolecular formation of the 2,3-dimethylbut-3-en-2-ol species from the 2,3-epoxy-2,3-dimethylbutane $(\mathrm{R} \rightarrow \mathrm{P} 3)$. Whatever the considered temperatures, the unimolecular rate constant for the formation of the 2,3-dimethylbut-3-en-2-ol species (product P3) is larger than that obtained for the products $\mathbf{P 1}$ and P2, which is in line with a reduction of the activation energy barrier, by 1.11 and $18.82 \mathrm{kcal} \mathrm{mol}^{-1}$, respectively on the corresponding chemical reaction pathways. Indeed, the obtained TST and RRKM results (Table 5) indicate that rate constant for the $\mathrm{R} \rightarrow \mathrm{P} 3$ unimolecular reaction is larger than the rate constants obtained for the other decomposition pathways.

An Arrhenius plot of the obtained unimolecular rate constants by means of RRKM theory for pathways 1-3, based on the UM06-2x energy profiles (see Figure 5) obviously confirms that the production of the 2,3-dimethylbut-3-en-2-ol (P3) species will therefore clearly predominate over the formation of the other products at a pressure of 1.0 bar and over the temperature range 661.5-729.1 K. The same observation holds for pressures ranging from $10^{-12}$ to $10^{2}$ bars (Tables $\mathrm{S} 1 a-\mathrm{S} 1 i$ in the Supplementary information). As is to be expected, because of the involved positive energy barriers, these rate constants increase gradually with increasing temperatures. Thus, thermal decomposition process $\mathbf{1}$ is thermodynamically 
favored over the elimination processes 2 and 3, while from a kinetic viewpoint, the reaction pathway $\mathbf{3}$ is more favorable channel.

Table 5. Unimolecular rate constants $\left(\right.$ in $\mathrm{s}^{-1}$ ) for the reported reaction channels obtained by means of TST and RRKM theories ( $P=1$ bar), according to the computed UM06-2x/aug-ccpVTZ energy barrier.

\begin{tabular}{|c|c|c|c|c|c|c|}
\hline \multirow{2}{*}{ Temperature (K) } & \multicolumn{3}{|c|}{ TST } & \multicolumn{3}{|c|}{ RRKM } \\
\hline & $\begin{array}{c}\mathrm{R} \rightarrow \mathrm{P} 1 \\
(\text { Reaction } \mathbf{1})\end{array}$ & $\begin{array}{c}\mathrm{R} \rightarrow \mathrm{P} 2 \\
\text { (Reaction 2) }\end{array}$ & $\begin{array}{c}\mathrm{R} \rightarrow \mathrm{P} 3 \\
\text { (Reaction 3) }\end{array}$ & $\begin{array}{c}\mathrm{R} \rightarrow \mathrm{P} 1 \\
\text { (Reaction } \mathbf{1})\end{array}$ & $\begin{array}{c}\mathrm{R} \rightarrow \mathrm{P} 2 \\
\text { (Reaction 2) }\end{array}$ & $\begin{array}{c}\mathrm{R} \rightarrow \mathrm{P} 3 \\
\text { (Reaction 3) }\end{array}$ \\
\hline 661.5 & $1.87 \times 10^{-7}$ & $6.66 \times 10^{-10}$ & $1.35 \times 10^{-6}$ & $1.83 \times 10^{-7}$ & $6.60 \times 10^{-10}$ & $7.83 \times 10^{-7}$ \\
\hline 672.2 & $3.80 \times 10^{-7}$ & $1.46 \times 10^{-9}$ & $2.63 \times 10^{-6}$ & $3.73 \times 10^{-7}$ & $1.44 \times 10^{-9}$ & $1.55 \times 10^{-6}$ \\
\hline 681.1 & $6.74 \times 10^{-7}$ & $2.74 \times 10^{-9}$ & $4.53 \times 10^{-6}$ & $6.62 \times 10^{-7}$ & $2.72 \times 10^{-9}$ & $2.70 \times 10^{-6}$ \\
\hline 689.1 & $1.11 \times 10^{-6}$ & $4.78 \times 10^{-9}$ & $7.30 \times 10^{-6}$ & $1.10 \times 10^{-6}$ & $4.73 \times 10^{-9}$ & $4.39 \times 10^{-6}$ \\
\hline 696.3 & $1.74 \times 10^{-6}$ & $7.79 \times 10^{-9}$ & $1.11 \times 10^{-5}$ & $1.71 \times 10^{-6}$ & $7.72 \times 10^{-9}$ & $6.73 \times 10^{-6}$ \\
\hline 704.2 & $2.79 \times 10^{-6}$ & $1.32 \times 10^{-8}$ & $1.74 \times 10^{-5}$ & $2.75 \times 10^{-6}$ & $1.30 \times 10^{-8}$ & $1.07 \times 10^{-5}$ \\
\hline 713.2 & $4.74 \times 10^{-6}$ & $2.36 \times 10^{-8}$ & $2.87 \times 10^{-5}$ & $4.67 \times 10^{-6}$ & $2.34 \times 10^{-8}$ & $1.78 \times 10^{-5}$ \\
\hline 721.2 & $7.51 \times 10^{-6}$ & $3.91 \times 10^{-8}$ & $4.44 \times 10^{-5}$ & $7.39 \times 10^{-6}$ & $3.88 \times 10^{-8}$ & $2.77 \times 10^{-5}$ \\
\hline 729.1 & $1.17 \times 10^{-5}$ & $6.38 \times 10^{-8}$ & $6.76 \times 10^{-5}$ & $1.15 \times 10^{-5}$ & $6.32 \times 10^{-8}$ & $4.25 \times 10^{-5}$ \\
\hline
\end{tabular}

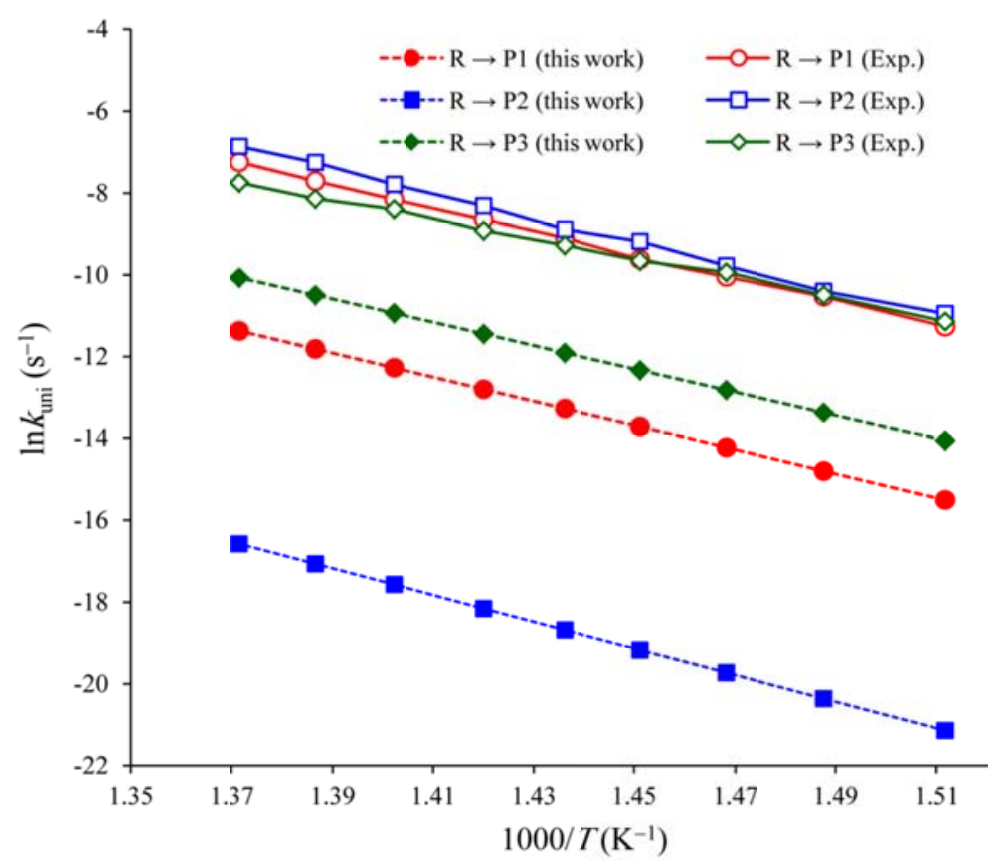

Figure 5. Arrhenius plot of the obtained RRKM unimolecular rate constants [for $\mathrm{R} \rightarrow \mathrm{P} i(i=1-3)$ ] at the UM06-2x/aug-cc-pVTZ level of theory. Legend: $(\bullet)$ theoretical rate constant obtained for the $\mathrm{R} \rightarrow \mathrm{P} 1$ pathway; (ם) theoretical rate constant obtained for the $\mathrm{R} \rightarrow \mathrm{P} 2$ pathway; $(\diamond)$ experimental rate constant obtained for the $\mathrm{R} \rightarrow \mathrm{P} 3$ pathway; (O) experimental rate constant obtained for the $\mathrm{R} \rightarrow \mathrm{P} 1$ pathway; $(\square)$ experimental rate constant obtained for the $\mathrm{R} \rightarrow \mathrm{P} 2$ pathway; $(\diamond)$ experimental rate constant obtained for the $\mathrm{R} \rightarrow \mathrm{P} 3$ pathway. 
For the sake of more quantitative insights into the regioselectivity of decomposition of pathways 1-3, branching ratios at pressure of 1 bar and at the studied temperatures are reported for the three retained chemical pathways in Table 6 . These branching rations have been calculated by means of TST, and RRKM theories, in conjunction with the UM06- $2 x$ / aug-cc-pVTZ estimates for unimolecular rate constants. Branching ratios significantly differ from the RRKM values obtained for the standard pressure (1 bar), specially at high temperatures, because of the extreme pressure dependence of the unimolecular kinetic rate constant characterizing pathway 3 .

$$
R(i)=\frac{k_{\mathrm{uni}}(i)}{k_{\mathrm{uni}}(\mathbf{1})+k_{\mathrm{uni}}(\mathbf{2})+k_{\mathrm{uni}}(\mathbf{3})} ; i=\mathbf{1}-\mathbf{3}
$$

At pressures ranging from $10^{-12}$ to $10^{2}$ bars and over the temperature range $661.5-729.1 \mathrm{~K}$, further RRKM estimates of these branching ratios are supplied in Tables S2a-S2h of the Supplementary information.

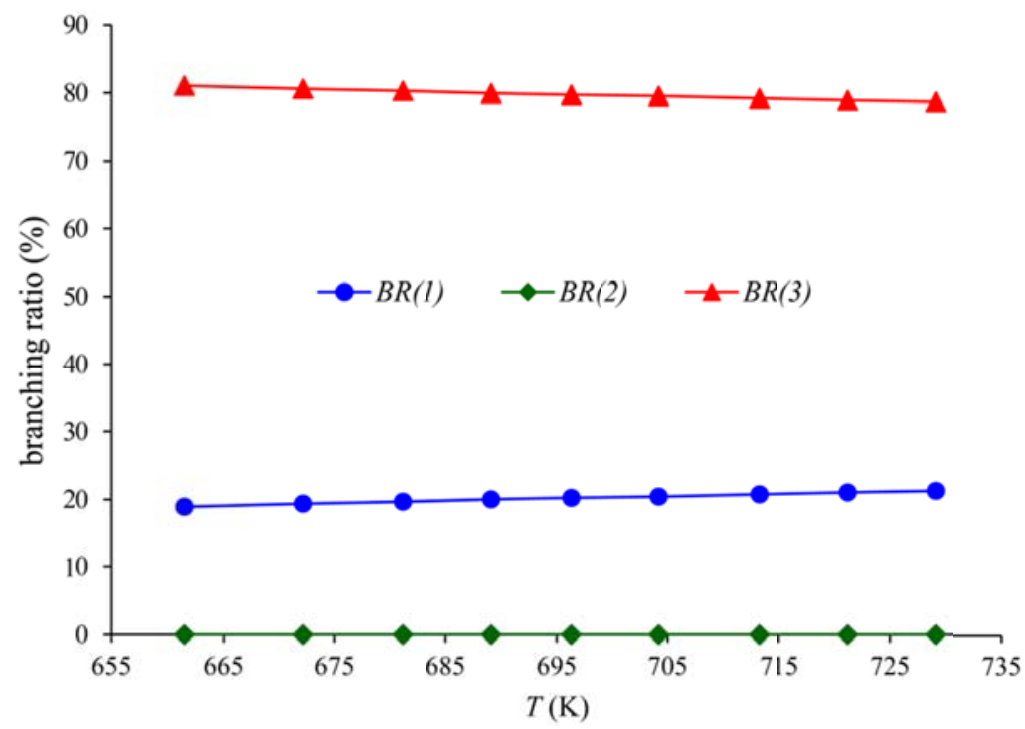

Figure 6. Evaluation of branching ratios in function of the temperature for pathways $\mathrm{R} \rightarrow \mathrm{P} i(i=1-3)$ using the UM06-2x/aug-cc-pVTZ approach. Legend: $(\bullet)$ data obtained for the $\mathrm{R} \rightarrow \mathrm{P} 1$ pathway; $(\bullet)$ data obtained for the $\mathrm{R} \rightarrow \mathrm{P} 2$ pathway; $(\boldsymbol{\Delta})$ data obtained for the $\mathrm{R} \rightarrow \mathrm{P} 3$ pathway. 
Table 6. Branching ratio for the reported reaction channels obtained by means of TST and RRKM theories ( $P=1$ bar), based on the computed UM06-2x energy profiles.

\begin{tabular}{|c|c|c|c|c|c|c|}
\hline \multirow{3}{*}{$T(\mathrm{~K})$} & \multicolumn{6}{|c|}{ Branching ratio (\%) } \\
\hline & \multicolumn{3}{|c|}{ TST } & \multicolumn{3}{|c|}{ RRKM } \\
\hline & $R(\mathbf{1})$ & $R(2)$ & $R(3)$ & $R(\mathbf{1})$ & $R(2)$ & $R(\mathbf{3})$ \\
\hline 661.5 & 12.161 & 0.043 & 87.795 & 18.931 & 0.068 & 81.001 \\
\hline 672.2 & 12.618 & 0.048 & 87.333 & 19.382 & 0.075 & 80.543 \\
\hline 681.1 & 12.945 & 0.053 & 87.003 & 19.675 & 0.081 & 80.244 \\
\hline 689.1 & 13.191 & 0.057 & 86.752 & 20.019 & 0.086 & 79.895 \\
\hline 696.3 & 13.543 & 0.061 & 86.396 & 20.242 & 0.091 & 79.666 \\
\hline 704.2 & 13.810 & 0.065 & 86.125 & 20.426 & 0.097 & 79.477 \\
\hline 713.2 & 14.165 & 0.071 & 85.765 & 20.762 & 0.104 & 79.134 \\
\hline 721.2 & 14.456 & 0.075 & 85.468 & 21.037 & 0.110 & 78.853 \\
\hline 729.1 & 14.742 & 0.080 & 85.177 & 21.271 & 0.117 & 78.612 \\
\hline
\end{tabular}

In Figure 7, we display the evolution of RRKM branching ratios for the decomposition processes via pathways 1-3 as a function of the temperature and pressure, respectively (see also Table 6 and Tables S3a-S3i of the Supplementary information). In line with the computed energy profile and kinetic rate constants (RRKM data) indicate that at temperatures ranging from 661.5 to $729.1 \mathrm{~K}$, the production of the 2,3-dimethylbut-3-en-2-ol species (via pathway 3) clearly predominates the overall reaction mechanism at all studied temperatures, and this down to extremely low pressures, larger than $10^{-12}$ bar. Nevertheless, the regioselectivity of the reaction decreases with increasing temperatures and decreasing pressures.

The reader is referred again to Figure 5 for an Arrhenius plot of the obtained RRKM estimates at a pressure of 1.0 bar for the decomposition processes of the 2,3-epoxy-2,3dimethylbutane, according to the UM06-2x/aug-cc-pVTZ estimates of energy barriers. This Figure clearly confirms that the production of the 2,3-dimethylbut-3-en-2-ol (P3) dominates the reaction mechanism under atmospheric pressure and at temperatures ranging from 661.5 to $729.1 \mathrm{~K}$. The same conclusion holds at much higher and lower pressures $\left(10^{-12}-10^{2}\right.$ bar $)$ (Tables S1a-S1 $i$ of the Supplementary information). 


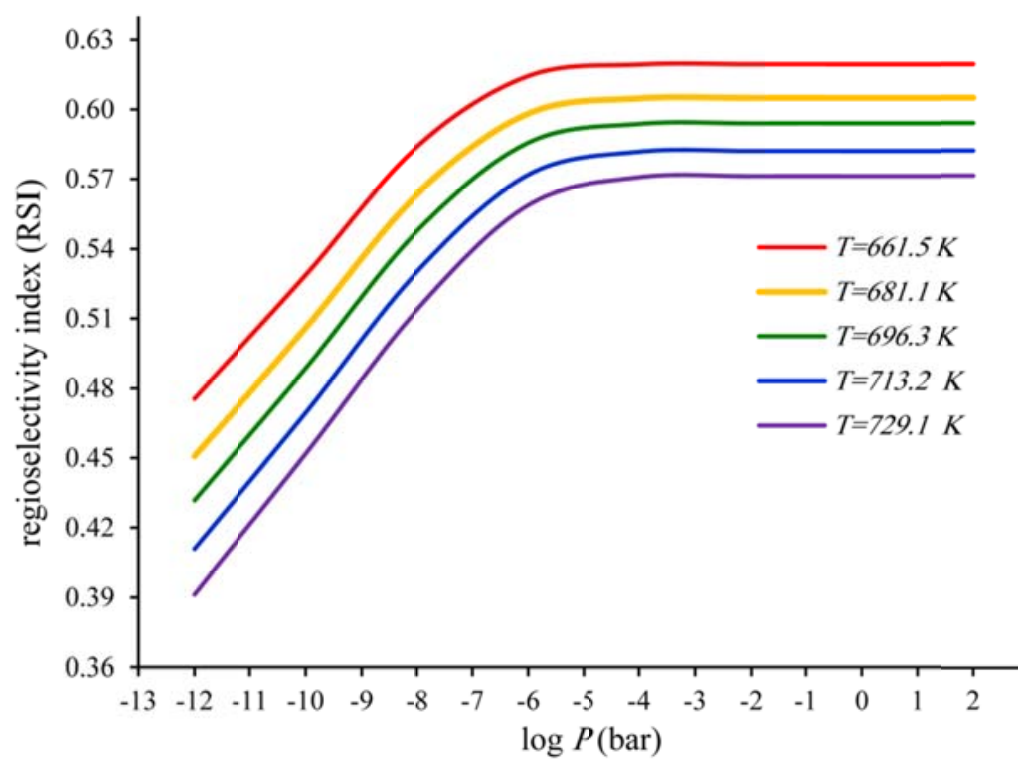

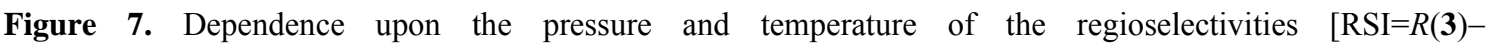
$[R(\mathbf{1})+R(\mathbf{2})] / R(\mathbf{1})+R(\mathbf{2})+R(\mathbf{3})]$ of decomposition processes of 2,3-epoxy-2,3-dimethylbutane, according to the RRKM estimates of unimolecular rate constants $\left[k_{\text {uni }}(\mathbf{1}), k_{\text {uni }}(2), k_{\text {uni }}(3)\right]$ supplied in Tables $\mathrm{S} 3 \mathrm{a}-\mathrm{S} 3 \mathrm{e}$ (see Supplementary information), based on UM06-2x/aug-cc-pVTZ energy profiles.

Since the involved energy barriers are large, the formation of the products $\mathbf{P 1}$ and $\mathbf{P} 2$ is characterized by significantly lower rate constants at the considered temperatures, compared with the formation of the product P3: the conversion of the 2,3-epoxy-2,3-dimethylbutane adducts into the product $\mathbf{P 3}$ through thermal decomposition is from a kinetic view point at least $\sim 3.7$ to 4.3 times larger than the conversion of the 2,3-epoxy-2,3-dimethylbutane species into the products $\mathbf{P 1}$ and $\mathbf{P} 2$ at the considered temperatures.

Inspection of Figure 8 and Table 5 shows that the RRKM unimolecular rate constants obtained for the reported chemical reaction pathways increase with increasing temperatures. Furthermore, upon inspecting the RRKM data displayed in Figure 8, it appears quite clearly that, in line with rather larger energy barriers, ranging from 59.37 to $66.34 \mathrm{kcal} \mathrm{mol}^{-1}$, pressures larger than $10^{-6}$ bar are in general sufficient for ensuring a saturation within $1 \%$ accuracy of the computed unimolecular kinetic rate constants compared with the highpressure limit (TST) of the RRKM unimolecular rate constants. Therefore for pressures lower than $10^{-6}$ bar, the fall-off expression is necessary for the kinetic modeling.

At a pressure of 1 bar, detailed inspection of Table 5 shows that ratios between the TST and $\mathrm{RRKM}$ estimates for pathway 3 (i.e. $\mathrm{R} \rightarrow \mathrm{P} 3$ ), rate constant decreases from $\sim 1.72$ to $\sim 1.59$ as 
the temperature increases from 661.5 to $729.1 \mathrm{~K}$. The differences are due to the applied tunneling effects to the TST rate constants.

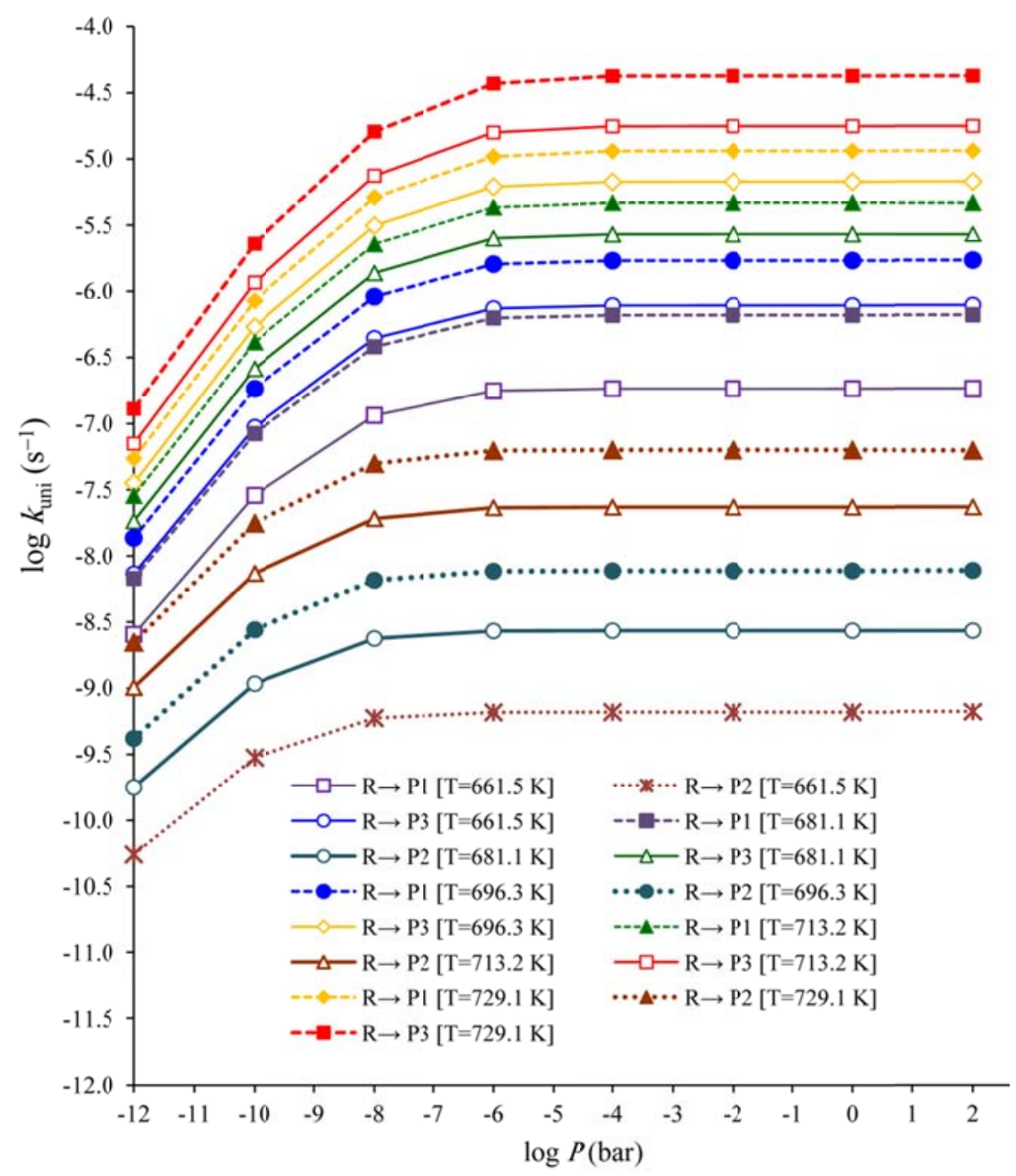

Figure 8. Pressure dependence of the unimolecular rate constants for the $\mathrm{R} \rightarrow \mathrm{P} i(\mathrm{i}=1-3)$ reaction steps according to the UM06-2x/aug-cc-pVTZ energy profiles.

\section{Bonding evolution theory (BET) study of favorable unimolecular reaction}

To get more insight into the nature of bonding along the reaction path 3 , the plots of Electron Localization Function (ELF) are visualized with the aid of the Multiwfn package ${ }^{35}$ to analyze the areas of charge concentration. The ELF function was originally proposed by Becke and Edgecombe ${ }^{36}$ to provide an orbital independent description of the electron localization. For a system described by single-Slater determinantal wavefunction built from Hartree-Fock or Kohn-Sham orbitals $\varphi_{\mathrm{i}}$, the ELF can be given by the following expression 
$\mathrm{ELF}=\eta(\mathbf{r})=\frac{1}{1+\left(D_{\sigma}(\mathbf{r}) / D_{\sigma}^{\mathrm{o}}(\mathbf{r})\right)^{2}}$

where $D_{\sigma}(\mathbf{r})=\frac{1}{2} \sum_{i}^{\mathrm{occ}}\left|\nabla \phi_{\mathrm{i}}\right|^{2}-\frac{1}{8}\left[\left(\left|\nabla \rho_{\alpha}(\mathbf{r})\right|^{2} / \rho_{\alpha}(\mathbf{r})\right)+\left(\left|\nabla \rho_{\beta}(\mathbf{r})\right|^{2} / \rho_{\beta}(\mathbf{r})\right)\right] \quad$ as $\quad$ a measure of electron localization has the physical meaning of the excess of local kinetic energy density due to Pauli's repulsion and $D_{\sigma}^{\circ}(\mathbf{r})=\frac{3}{10}\left(6 \pi^{2}\right)^{\frac{2}{3}}\left[\rho_{\alpha}(\mathbf{r})^{\frac{5}{3}}+\rho_{\beta}(\mathbf{r})^{\frac{5}{3}}\right]$ is the Thomas-Fermi kinetic energy density, which corresponds to a uniform electron gas with spin density equal to the local value of $\rho(\mathbf{r}){ }^{37}$ The ELF takes in every point of space a value on to the range $0 \leq \mathrm{ELF} \leq 1$ with the upper limit $\mathrm{ELF}=1$ corresponds to perfect localization, ELF=0.5 corresponds to electron-gas-like pair probability, and the ELF $=0$ corresponds to perfect delocalization. ${ }^{38}$ Color-filled maps of the electron localization function along the IRC of reaction path 3 , in the molecular plane defined by plane of the $\mathrm{C}_{2}-\mathrm{O}-\mathrm{C}_{1}$, are obtained at the UM06-2x/aug-cc-pVTZ level of theory and presented in Figure 9. Color-filled maps clearly show that core electrons are localized on carbon, oxygen and hydrogen atoms. The BET study of the reaction path 3 indicates that this reaction along the intrinsic reaction coordinate can be topologically characterized by three differentiated successive structural stability domains (SSDs). The first SSD, begins from reactant and ends before $\mathrm{R} x=0.31332 \mathrm{amu}^{1 / 2} \mathrm{Bohr}$. At the start point, the hydrogen atom is attached to the $C_{1}$ atom in which along the reaction coordinate at $\mathrm{R} x=0.10422 \mathrm{amu}^{1 / 2}$ Bohr decreasing of the ELF function is observable. At $\mathrm{R} x=0.31332 \mathrm{amu}^{1 / 2} \mathrm{Bohr}$ the covalent $\mathrm{C}_{1}-\mathrm{H}$ bond is completely broken and ELF function is less than 0.7. The final phase starts from $\mathrm{R} x=0.41791 \mathrm{amu}^{1 / 2} \mathrm{Bohr}$ and continues until the formation of new covalent bond $\mathrm{O}_{2}-\mathrm{H}$ completes. 

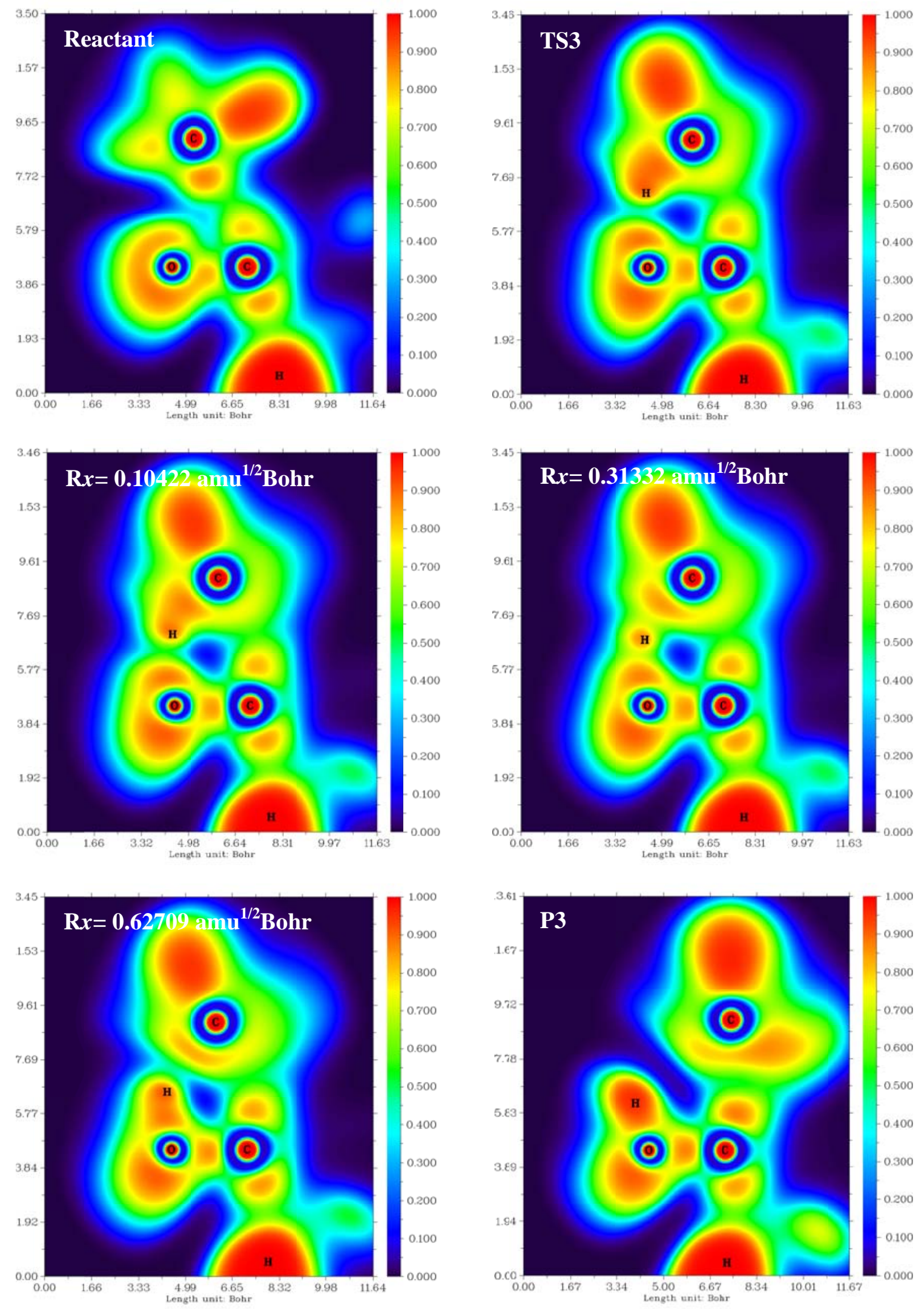

Figure 9. Color-filled maps of the electron localization function along the IRC of reaction path 3 , in the molecular plane defined by plane of the $\mathrm{C}_{6}-\mathrm{O}_{8}-\mathrm{C}_{1}$. The ELF values [0 to 1] are mapped on a blue-green-red color scale indicated on the right of each representation. Blue and red colors indicate respectively no electron and high electron localization. 


\section{Conclusion}

The thermal decomposition processes of 2,3-epoxy-2,3-dimethylbutane have been studied computationally using density functional theory along with various exchange-correlation functionals ( $\omega \mathrm{B} 97 \mathrm{XD}$, and UM06-2x) and an extremely large basis set (aug-cc-pVTZ). Note that the UM06- $2 x$ functional has been especially designed for accurate studies of chemical reactions, both from a thermodynamic and kinetic viewpoint, ${ }^{39}$ whereas a main advantage of the $\omega \mathrm{B} 97 \mathrm{XD}$ functional is a consistent treatment of dispersion forces. The calculated energy profiles have been supplemented with calculations of kinetic rate constants and branching ratios under atmospheric pressure and in the fall-off regime, down to pressure of $10^{-12}$ bar, using conventional TST and RRKM theories. The supplied data indicate that, under a kinetic control of the reaction, the 2,3-dimethylbut-3-en-2-ol species is chemically much more reactive than the other products. The supplied data indicate that, under a thermodynamical viewpoint, the most abundant product derived from the decomposition of the 2,3-epoxy-2,3dimethylbutane is the 3,3-dimethylbutan-2-one species.

In line with the experimental observations by Flowers et al., ${ }^{5}$ the correspondingly obtained branching ratios indicate that the kinetically most efficient process at temperatures ranging from 661.5 to $729.1 \mathrm{~K}$ corresponds to thermal decomposition of 2,3-epoxy-2,3dimethylbutane to the 2,3-dimethylbut-3-en-2-ol species. These branching rations also indicate that the regioselectivity of the reaction decreases with increasing temperatures and decreasing pressures. RRKM calculations show in particular that overwhelmingly high

pressures, larger than $10^{-6}$ bar, would be required for restoring the validity of this approximation for all reaction channels.

The bonding evolution theory analysis of reaction pathway 3 indicates that all topological changes along the reaction coordinate occur after passing the reactant from transition state at $\mathrm{R} x=0.10422-0.31332 \mathrm{amu}^{1 / 2}$ Bohr by three differentiated successive structural stability domains.

\section{Acknowledgements}

All calculations presented in this work have been performed at the Flemish Supercomputer Center (Vlaams Supercomputer Centrum). This cluster has been financed by budgets obtained from the Katholieke Universiteit Leuven, as well as from individual contributions by users, and funding obtained from the Hercules foundation and the Flemish government. The authors thank anonymous referees for highly relevant comments. 


\section{Supplementary information}

Supplementary data (Tables S1-S3, and a video file) associated with this article can be found, in the online version. Table S1: Unimolecular rate constants for all reaction steps involved in the reported chemical pathways (results obtained by means of RRKM theory at different pressures and temperatures, according to the computed UM06-2x/aug-cc-pVTZ energy profiles); Table S2: Kinetic rate constants (in $\mathrm{s}^{-1}$ ), and branching ratios in the reported chemical pathways at ambient temperature and different pressures using the RRKM theory, according to the computed UM06-2x/aug-cc-pVTZ energy profiles; Table S3: Dependence upon the pressure and temperature of the regioselectivities

$[\mathrm{RSI}=R(\mathbf{3})-[R(\mathbf{1})+R(\mathbf{2})] / R(\mathbf{1})+R(\mathbf{2})+R(\mathbf{3})]$ of thermal decomposition of 2,3-epoxy-2,3dimethylbutane, according to the RRKM estimates of unimolecular rate constants $\left[k_{\text {uni }}(\mathbf{1})\right.$, $\left.k_{\text {uni }}(2), k_{\text {uni }}(3)\right]$ based on UM06-2x/aug-cc-pVTZ energy profiles; Video file: ELF pattern of bonding changes along the IRC path of reaction 3.

\section{References}

[1]. (a) W. W. Heckert, E. Mack, J. Amer. Chem. Soc., 1929, 51, 2706; (b) C. J. M. Fletcher and G. K. Rollefson, J. Amer. Chem. Soc., 1936, 58, 2135; (c) K. H. Mueller and W. D. WaIters, J. Amer. Chem. Soc., 1951, 73, 1458; (d) K. H. Mueller and W. D. WaIters, J. Amer. Chem. Soc., 1954, 76, 330; (e) M. L. Neufeld and A. T. Blades, Can. J. Chem., 1963, 41, 2956.

[2]. F. P. Lossing, K. U. Ingold and A. W. Tickner, Discuss. Faraday Soc., 1953, 14, 34.

[3]. (a) H. W. Thompson and M. Meissner, Trans. Faraduy Soc., 1936, 32, 1451; (b) T. J. Hardwick, Can. J. Chem., 1968, 46, 2454; (c) A. T. Blades, Can. J. Chem., 1968, 46, 3283.

[4]. S. W. Benson, J. Chem. Phys., 1964, 40, 105.

[5]. M. C. Flowers, R. M. Parker and M. A. Voisey, J. Chem. Soc. B, 1970, 239.

[6]. H. Eyring, J. Chem. Phys., 1935, 3, 107.

[7]. H. S. Johnston, Gas Phase Reaction Rate Theory, Roland Press, New York, 1966.

[8]. K. J. Laidler, Theories of Chemical Reaction Rates, McGraw-Hill, New York, 1969.

[9]. R. E. Weston and H. A. Schwartz, Chemical Kinetics, Prentice-Hall, New York, 1972.

[10]. D. Rapp, Statistical Mechanics, Holt, Rinehart, and Winston, New York, 1972.

[11]. E. E. Nikitin, Theory of Elementary Atomic and Molecular Processes in Gases, Clarendon Press, Oxford, 1974. 
[12]. I. W. M. Smith, Kinetics and Dynamics of Elementary Gas Reactions, Butterworths, London, 1980.

[13]. A.E. Reed, L.A. Curtiss and F. Weinhold, Chem. Rev., 1988, 88, 899.

[14]. J. D. Chai and M. Head-Gordon, Phys. Chem. Chem. Phys., 2008, 10, 6615.

[15]. Y. Zhao and D. G. Truhlar, Theor. Chem. Acc., 2008, 120, 215.

[16]. T. H. Dunning Jr., J. Chem. Phys., 1989, 90, 1007.

[17]. P. J. Robinson and K. A. Holbrook, Unimolecular Reactions, Wiley, New York, 1972.

[18]. J. I. Steinfeld, J. S. Francisco and W. L. Hase, Chemical Kinetics and Dynamics. Prentice-Hall, Englewood Cliffs, NJ, 1999.

[19]. H. Eyring, S. H. Lin and S. M. Lin, Basic Chemical Kinetics, Wiley, New York, 1980.

[20]. M. J. Frisch, G. W. Trucks, H. B. Schlegel, G. E. Scuseria, M. A. Robb, J. R. Cheeseman, G. Scalmani, V. Barone, B. Mennucci, G. A. Petersson, H. Nakatsuji, M. Caricato, X. Li, H. P. Hratchian, A. F. Izmaylov, J. Bloino, G. Zheng, J. L. Sonnenberg, M. Hada, M. Ehara, K. Toyota, R. Fukuda, J. Hasegawa, M. Ishida, T. Nakajima, Y. Honda, O. Kitao, H. Nakai, T. Vreven, J. A. Montgomery Jr., J. E. Peralta, F. Ogliaro, M. Bearpark, J. J. Heyd, E. Brothers, K. N. Kudin, V. N. Staroverov, R. Kobayashi, J. Normand, K. Raghavachari, A. Rendell, J. C. Burant, S. S. Iyengar, J. Tomasi, M. Cossi, N. Rega, J. M. Millam, M. Klene, J. E. Knox, J. B. Cross, V. Bakken, C. Adamo, J. Jaramillo, R. Gomperts, R. E. Stratmann, O. Yazyev, A.J. Austin, R. Cammi, C. Pomelli, J.W. Ochterski, R.L. Martin, K. Morokuma, V.G. Zakrzewski, G.A. Voth, P. Salvador, J. J. Dannenberg, S. Dapprich, A. D. Daniels, O. Farkas, J. B. Foresman, J. V. Ortiz, J. Cioslowski and D. J. Fox, Gaussian 09 Inc, Wallingford, CT, USA, Gaussian Inc, Wallingford, CT, 2009.

[21]. R. Dennington II, T. Keith, J. Millam, K. Eppinnett, W. L. Hovell and R. Gilliland, GaussView, Version 5.0; Semichem, Inc.: Shawnee Mission, KS, 2003.

[22]. (a) H. P. Hratchian and H. B. Schlegel, J. Chem. Phys., 2004, 120, 9918; (b) H. P. Hratchian and H. B. Schlegel, Theory and Applications of Computational Chemistry: The First 40 Years, Elsevier, Amsterdam, 2005; (c) H. P. Hratchian and H. B. Schlegel, J. Chem. Theory Comput., 2005, 1, 61.

[23]. R. Jasiński, Comp. Theor. Chem., 2014, 1046, 93.

[24]. R. Jasiński, J. Fluor. Chem., 2014, 160, 29.

[25]. R. Chang, Physical Chemistry for the Biosciences, University Science Books, Sausalito: California, 2005.

[26]. J. W. Moore and R. G. Pearson, Kinetics and Mechanism-The Study of Homogeneous 
Chemical Reactions, 3rd ed., Wiley: New York, 1981.

[27]. H. H. Carstensen, A. M. Dean and O. Deutschmann, Proc. Combust. Inst., 2007, 31, 149.

[28]. (a) E. Wigner, J. Chem. Phys., 1937, 5, 720; (b) E. Wigner, Z. Phys. Chem. B, 1932, 19, 203.

[29]. F. M. Mourits and H. A. Rummens, Can J. Chem., 1977, 55, 3007.

[30]. S. Canneaux, F. Bohr and E. Henon, J. Comput. Chem., 2014, 35, 82.

[31]. J. Troe, J. Chem. Phys., 1977, 66, 4758.

[32]. R. J. Kee, F. M. Rupley, J. A. Miller, M. E. Coltrin, J. F. Grcar, E. Meeks, H. K. Moffat, A. E. Lutz, G. Dixon-Lewis, M. D. Smooke, J. Warnatz, G. H. Evans, R. S. Larson, R. E. Mitchell, L. R. Petzold, W. C. Reynolds, M. Caracotsios, W. E. Stewart, P. Glarborg, C. Wang, C. L. McLellan, O. Adigun, W. G. Houf, C. P. Chou, S.F. Miller, P. Ho, P. D. Young, D. J. Young, D. W. Hodgson, M. V. Petrova and K. V. Puduppakkam, CHEMKIN, Reaction Design, San Diego, CA, 2010.

[33]. G. S. Hammond, J. Am. Chem. Soc., 1953, 77, 334.

[34]. N. Agmon and R. D. Levine, Chem. Phys. Lett., 1977, 52, 197.

[35]. T. Lu and F. Chen, J. Comput. Chem., 2012, 33, 580.

[36]. A. D. Becke and K. E. Edgecombe, J. Chem. Phys., 1990, 92, 5397.

[37]. X. Krokidis, S. Noury and B. Silvi, J. Phys. Chem. A, 1997, 101, 7277.

[38]. L.P. Ding, X. Y. Kuang, P. Shao and M. M. Zhong, Dalton Trans., 2013, 42, 8644.

[39]. A. Shiroudi and M. S. Deleuze, Comp. Theor. Chem., 2015, 1074, 26. 